\title{
Successful Colchicine Therapy in a Patient With Follicular Bronchiolitis Presumed to Be Asthma
}

\author{
Ozlem Goksel MD, Deniz Nart MD, Ayse Gul Ergonul MD, \\ Fidan Sever MD, and Tuncay Goksel MD
}

\begin{abstract}
Follicular bronchiolitis (FB) is a rare small-airway pathology that is associated mainly with connective tissue diseases. This case report presents a new, diagnosed, different airway disease in a non-smoker with rheumatoid arthritis in remission who was treated for presumed asthma, but was not controlled. She was ultimately diagnosed with FB after video-assisted thoracoscopic surgery. The clinical findings of FB were controlled successfully by colchicine after she did not respond to systemic steroid therapy. This is the first case report of $\mathrm{FB}$ associated with rheumatoid arthritis that responded to colchicine. Key words: follicular bronchiolitis; colchicine; asthma; rheumatoid arthritis. [Respir Care 2015;60(7):e122-e124. () 2015 Daedalus Enterprises]
\end{abstract}

\section{Introduction}

Follicular bronchiolitis (FB) is a rare small-airway pathology that is characterized by bronchiolocentric hyperplastic lymphoid follicles. It may occur secondary to antigenic stimulation and may be part of the general lymphoid response of the lung. FB has been reported in patients with rheumatoid arthritis (RA), Sjögren's syndrome, immunodeficiency syndrome, and hypersensitivity reactions. ${ }^{1-6}$ As FB is occasionally confused with asthma or COPD, FB has also been reported with asthma. ${ }^{7}$ There is insufficient experience regarding the treatment of FB.

\section{Case Report}

A 40-y-old female was referred to our clinic with uncontrolled asthma. She was a non-smoker and had been diagnosed with RA 16 y earlier based on pain in the joints of her feet (inflammatory arthritis involving metatarsophalangeal joints in the feet for $>3$ months, positive rheumatoid factor, and elevated C-reactive protein levels and

\footnotetext{
Drs O Goksel and T Goksel are affiliated with the Department of Pulmonary Medicine, Dr Nart is affiliated with the Department of Pathology, and Dr Ergonul is affiliated with the Department of Thoracic Surgery, Ege University School of Medicine, Izmir, Turkey. Dr Sever is affiliated with the Department of Pulmonary Medicine, Sifa University School of Medicine, Izmir, Turkey.
}

The authors have disclosed no conflicts of interest. erythrocyte sedimentation rate). She reported that the first 2 episodes were controlled with non-steroidal anti-inflammatory drugs, but the last severe joint involvement $6 \mathrm{y}$ earlier did not respond to this treatment, so she was treated with sulfasalazine and systemic steroids for $1 \mathrm{y}$. Since then, she had no joint complaints and had not been on anti-rheumatic therapy. She reported that she was diagnosed with asthma 3 y earlier, with wheezing and coughing, and that her complaints had increased steadily over the past year despite taking asthma medication. She had no history of environmental or occupational exposure. Common prick and intradermal tests for general atopy were negative. A hemogram showed no eosinophilia. Pulmonary function tests showed an FVC of $2.25 \mathrm{~L}(77 \%)$, an $\mathrm{FEV}_{1}$ of $1.65 \mathrm{~L}(66 \%)$, an $\mathrm{FEV}_{1} / \mathrm{FVC}$ of 0.73 , and a diffusing capacity of the lung for carbon monoxide of $47 \mathrm{~mL} / \mathrm{min} / \mathrm{mm} \mathrm{Hg}$ (68\%). The early and late reversibility tests were negative in the pulmonary function tests. Because of the low $\mathrm{FEV}_{1}$, a nonspecific bronchial provocation test with methacholine was not planned. The clinical presentation in this non-atopic female patient was not compatible with asthma; she did not report an episodic course

\footnotetext{
Correspondence: Ozlem Goksel MD, Pulmonary, Immunology and Allergy, Department of Pulmonary Medicine, Asthma and Allergy Laboratory and Outpatient Clinic, Ege University, School of Medicine, Bornova, 35100 Izmir, Turkey. E-mail: goksel.ozlem@gmail.com.
}

DOI: $10.4187 /$ respcare. 03610 


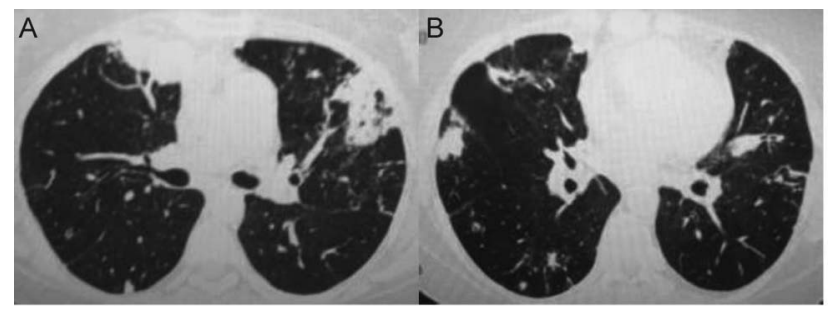

Fig. 1. Pre-treatment computed tomography features: bilateral bronchial wall thickening, bronchiectasis, and bilateral patchy areas of consolidation accompanied by peribronchial fibrosis in the upper lobes. A: Anterior and lingular segments. B: Anterior segment.

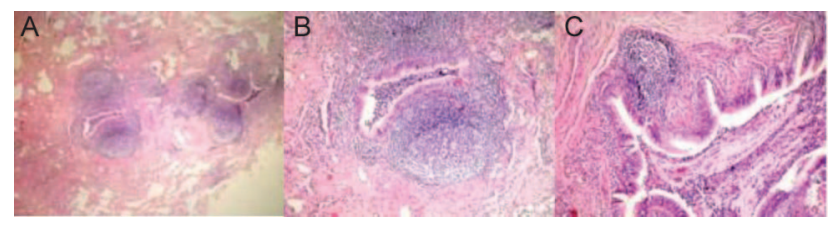

Fig. 2. A: Lymphoid follicles with well-formed germinal centers in a peribronchiolar distribution. B: Eccentric peribronchiolar lymphoid follicle with a germinal center. There are inflammatory cells in the bronchial lumen. C: Mucus and inflammatory cells are seen in the lumen. Mucinous metaplasia is present in the bronchiolar epithelium. There is a small lymphoid follicle along the bronchiole.

(bronchospasm attacks triggered by allergens/nonspecific asthma triggers). Thus, the previous asthma diagnosis was excluded.

Thoracic computed tomography showed bilateral bronchial wall thickening, bronchiectasis, and bilateral patchy areas of consolidation accompanied by peribronchial fibrosis in the upper lobes. These lesions were dominant in the anterior segment and in the right, anterior, and lingular segments in the left side (Fig. 1). Bronchoscopy was normal; bronchoalveolar lavage showed $18 \%$ neutrophils, $14 \%$ lymphocytes, $1 \%$ eosinophils, and $67 \%$ macrophages. A transbronchial biopsy was not diagnostic. Sulfasalazine toxicity was excluded, as it had not been used for $5 \mathrm{y}$. Chronic eosinophilic pneumonia, allergic bronchopulmonary aspergillosis, and Churg-Strauss syndrome were excluded because there was no peripheral or bronchoalveolar lavage eosinophilia; a negative skin test and normal total immunoglobulin E; and no peripheral neuropathy, eosinophilia, skin involvement findings, or sinusitis, respectively. Video-assisted thoracoscopic surgery was performed to obtain tissue for a definitive diagnosis. The histopathological examination revealed FB characterized by bronchiolocentric hyperplastic lymphoid follicles (Fig. 2). FB was considered to have developed due to RA. The patient was started on prednisolone at $1 \mathrm{mg} / \mathrm{kg}$, but it was discontinued due to severe steroid-induced side effects and continued wheezing and coughing for 4 months. She was started on $0.5 \mathrm{mg}$ of oral colchicine twice daily. The colchicine ther-

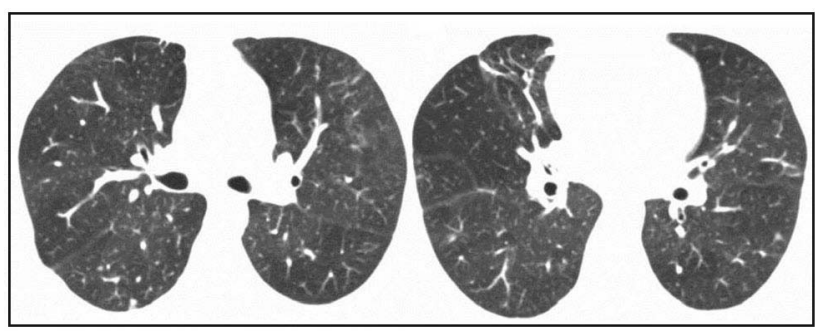

Fig. 3. Post-treatment computed tomography features. All lesions were significantly improved.

apy produced an improvement in her clinical signs, with no bronchospasm or coughing. The treatment was continued for $4 \mathrm{y}$, and the patient showed significantly improved computed tomography findings (Fig. 3) and breath sounds. During this period, no joint complaints due to RA or respiratory symptoms recurred. The pulmonary function test at the 4-y follow-up showed an FVC of $2.33 \mathrm{~L}(83 \%)$, an $\mathrm{FEV}_{1}$ of $1.75 \mathrm{~L}(73 \%)$, an $\mathrm{FEV}_{1} / \mathrm{FVC}$ of 0.75 , and a diffusing capacity of the lung for carbon monoxide of $53 \mathrm{~mL} / \mathrm{min} / \mathrm{mm} \mathrm{Hg}(77 \%)$.

\section{Discussion}

In this case report, we present a rare airway disease due to RA. The patient was treated initially for presumed asthma, which was not controlled. After being diagnosed with FB, she was treated successfully with colchicine after not responding to steroids.

The literature includes a case of FB associated with asthma and chronic eosinophilia. ${ }^{6} \mathrm{FB}$ is a disease of exacerbations, complicated by infections. Steroid therapy has clinical benefit in half of all patients, ${ }^{8}$ but was not effective in our patient. Therefore, colchicine treatment was initiated, followed by improved clinical findings, pulmonary function tests, and radiological images without side effects.

The exact mechanism of the benefit of colchicine in this patient with FB is not clear. The therapeutic effect is thought to be related to the ability of colchicine to disrupt microtubules and to concentrate in leukocytes, especially granulocytes, where it can reach high concentrations, even at low oral doses. Neutrophilic inflammation has been reported in FB cases, ${ }^{8-10}$ as in our case. This neutrophilic inflammation can predispose to a colchicine response. Colchicine has been used to treat different clinical features related to RA, such as neutrophilic dermatosis, methotrexate-induced accelerated nodulosis, pustular vasculitis, and recurrent pericarditis. ${ }^{911-13}$ Important data regarding longterm colchicine use was obtained from patients with familial Mediterranean fever and Behçet's disease. ${ }^{14,15} \mathrm{Col}-$ chicine is known to have an effect on the pulmonary fibrotic 


\section{Colchicine in Follicular Bronchiolitis}

process. Colchicine combined with prednisone has been used to treat idiopathic pulmonary fibrosis. ${ }^{16}$

In conclusion, we present a rare case of $\mathrm{FB}$ associated with RA that was initially presumed to be asthma. In our case, colchicine improved the symptoms and signs of FB. To our knowledge, this is the first report of FB associated with RA that responded to colchicine, but not to steroids. This case suggests that colchicine should be included in the treatment options for FB.

\section{REFERENCES}

1. Ryu JH. Classification and approach to bronchiolar diseases. Curr Opin Pulm Med 2006;12(2):145-151.

2. Ryu JH, Myers JL, Swensen SJ. Bronchiolar disorders. Am J Respir Crit Care Med 2003;168(11):1277-1292.

3. Hayakawa H, Sato A, Imokawa S, Toyoshima M, Chida K, Iwata M. Bronchiolar disease in rheumatoid arthritis. Am J Respir Crit Care Med 1996;154(5):1531-1536.

4. Fortoul TI, Cano-Valle F, Oliva E, Barrios R. Follicular bronchiolitis in association with connective tissue diseases. Lung 1985;163(5): 305-314.

5. Howling SJ, Hansell DM, Wells AU, Nicholson AG, Flint JD, Müller NL. Follicular bronchiolitis: thin-section CT and histologic findings. Radiology 1999;212(3):637-642.

6. Yousem SA, Colby TV, Carrington CB. Follicular bronchitis/bronchiolitis. Hum Pathol 1985;16(7):700-706.

7. Shimizu K, Konno S, Nasuhara Y, Tanino M, Matsuno Y, Nishimura M. A case of follicular bronchiolitis associated with asthma, eosin- ophilia, and increased immunoglobulin E. J Asthma 2010;47(10): 1161-1164.

8. Romero S, Barroso E, Gil J, Aranda I, Alonso S, Garcia-Pachon E. Follicular bronchiolitis: clinical and pathologic findings in six patients. Lung 2003;181(6):309-319.

9. Youn CS, Hwang JH, Cho KH, Yoon TY. Colchicine treatment in a patient with neutrophilic dermatosis associated with rheumatoid arthritis. J Dermatol 2000;27(12):782-787.

10. Kinoshita M, Higashi T, Tanaka C, Tokunaga N, Ichikawa Y, Oizumi K. Follicular bronchiolitis associated with rheumatoid arthritis. Intern Med 1992;31(5):674-677.

11. Abraham Z, Rozenbaum M, Rosner I. Colchicine therapy for lowdose-methotrexate-induced accelerated nodulosis in a rheumatoid arthritis patient. J Dermatol 1999;26(10):691-694.

12. Bose SK. Treatment of pustular vasculitis in rheumatoid arthritis with colchicine. Natl Med J India 1996;9(6):297-298.

13. Fernández-Muixí J, Vidal F, Bardají A, Richart C. Recurrent pericarditis and cardiac tamponade in rheumatoid arthritis: effectiveness of colchicine. Br J Rheumatol 1994;33(6):596-597.

14. Ben-Chetrit E, Levy M. Colchicine prophylaxis in familial Mediterranean fever: reappraisal after 15 years. Semin Arthritis Rheum 1991; 20(4):241-226.

15. Yurdakul S, Mat C, Tüzün Y, Ozyazgan Y, Hamuryudan V, Uysal $\mathrm{O}$, et al. A double-blind trial of colchicine in Behçet's syndrome. Arthritis Rheum 2001;44(11):2686-2692.

16. Ishizuka $T$, Hisada $T$, Monden $T$, Tsunekawa K, Iizuka $K$, Tsukagoshi $\mathrm{H}$, et al. A case of non-specific interstitial pneumonia effectively treated with a combination of prednisolone and colchicine, in which granulation tissue was extensive. Respirology 2005;10(4):541544 . 